\title{
ANALISIS TOTAL QUALITY MANAGEMENT (TQM) PADA PENDIRIAN TK ISLAM TERPADU MUTIARA PLUS BANGUNTAPAN
}

\author{
MUHAMMAD ABDUL LATIF \\ Universitas Islam Negeri Sunan Kalijaga Yogyakarta \\ Email: abdullatif.ful@gmail.com \\ ERNI MUNASTIWI \\ Universitas Islam Negeri Sunan Kalijaga Yogyakarta \\ Email: erni.munastiwi18@gmail.com \\ DESKA PUSPITA \\ Universitas Islam Negeri Sunan Kalijaga Yogyakarta \\ Email: puspitadeska@gmail.com \\ ADINDA PUTRI AMANAH \\ Universitas Islam Negeri Sunan Kalijaga Yogyakarta \\ Email: putri.amanah@gmail.com
}

\begin{abstract}
The advance of times is the biggest challenge of educational institutions, especially in Early Childhood Education Institutions which must strive in totality to become quality institutions. The emergence of inadequate PAUD institutions or accreditation that has not yet reached PAUD institution accreditation standards is a problem in this study. The purpose of the study was to examine the management analysis of the establishment of PAUD institutions with a Total Quality Management (TQM) approach at TK IT Mutiara Plus Banguntapan, Bantul. This research method uses qualitative research with a case study approach. Data collection techniques with observation, interviews, and documentation. The analysis used the Milles and Huberman model. The results of this study found that the Management of PAUD Institution in TK IT Mutiara Plus Banguntapan, Bantul was well organized. After being analyzed by TQM there are no principles or references that are not applied. This is evidenced by the advancement in the quality of TK IT Mutiara Plus Banguntapan, Bantul institutions from the initial establishment until now.
\end{abstract}

Keywords: management of paud; total quality management (tqm); early childhood education. 


\section{Abstrak}

Majunya zaman menjadi tantangan terbesar lembaga pendidikan terutama pada lembaga Pendidikan Anak Usia Dini (PAUD) yang harus berupaya secara totalitas menjadi lembaga yang berkualitas. Munculnya lembaga-lembaga PAUD yang kurang baik atau akreditasi yang belum mencapai standar akreditasi lembaga PAUD menjadi problem pada penelitian ini. Tujuan penelitian adalah mengkaji tentang analisis manajemen pendirian lembaga PAUD dengan Total Quality Management (TQM) approach di TK IT Mutiara Plus Banguntapan, Bantul. Metode penelitian ini menggunakan penelitian jenis kualitatif dengan pendekatan studi kasus. Teknik pengumpulan data dengan observasi, wawancara, dan dokumentasi. Analisis yang digunakan model Milles and Huberman. Hasil penelitian ini menemukan bahwa Manajemen Lembaga PAUD di TK IT Mutiara Plus Banguntapan, Bantul tersusun secara baik. Setelah di analisis dengan TQM tidak ditemukan prinsip ataupun acuan TQM yang tidak diterapkan. Hal ini dibuktikan dengan kemajuan kualitas lembaga TK IT Mutiara Plus Banguntapan, Bantul dari awal pendirian sampai sekarang.

Kata Kunci: Manajemen Lembaga PAUD; Total Quality Management; Pendidikan Anak Usia Dini

\section{PENDAHULUAN}

TQM adalah sebuah strategi usaha yang berorientasi pada kepuasan pelanggan dengan melibatkan seluruh anggota organisasi untuk mewujudkan sistem manajemen yang berkualitas (Diana, 2003, p. 4). TQM ini memiliki prinsip dengan berlandasan untuk memperbaiki secara terus-menerus dari suatu organisasi (Gaspersz, 2002, p. 6). Apabila ditarik ke ranah pendidikan, TQM tentu mampu untuk menjadikan lembaga pendidikan yang efektif dan mampu meningkatkan sistem pendidikan dengan berbagai variasi (Salih, 2008, p. 2), meningkatkan kualitas siswa agar berfikir kritis dan kreatif (Crawford \& Shutler, 1999, p. 67), dan mampu meningkatkan kualitas seluruh sistem (Töremen, Karakuş, \& Yasan, 2009, p. 30). Lembaga yang berkulitas tentu dimulai dari lembaga pendidikan yang paling fundamental, yakni lembaga PAUD.

Menurut Menteri Pendidikan dan Kebudayaan Nadiem Makarim menjelaskan bahwa: "pendidikan anak usia dini itu penting dilakukan untuk membentuk anak-anak negeri menjadi pribadi yang berkarakter sejak dini”. Kutipan tersebut memberikan gambaran perlunya mendidik anak sejak usia dini. Usia dini (0-8 tahun) merupakan usia yang memiliki pengaruh terhadap perkembangan selanjutnya sehingga sangat penting untuk diberikan stimulus. Apabila dilihat dari perkembangan otak anak usia dini mencapai $80 \%$ pada usia 8 tahun (Mulyasa, 2014, p. 2). Pencapaian $80 \%$ ini membuktikan bahwa anak usia dini memang cepat 
AWLADY: Jurnal Pendidikan Anak

Homepage: www.syekhnuriati.ac.id/jurnal/index.php/awlady

Email : pgrasyekhnurjati@gmail.com

P-ISSN: 2541-4658

E-ISSN: 2528-7427

merespon sesuatu apapun. Oleh karenanya, perlu memberikan stimulus yang tepat bagi anak usia dini baik di lingkungan keluarga, sekolah dan masyarakat. Namun, pada kenyataannya orang tua anak disibukkan dengan dunia kerja sehingga berdampak pada tidak terabaikan pendidikan anak pada jam-jam kerja 08.00 WIB s/d 16.00 WIB. Hal ini menjadi kesempatan bagi masyarakat untuk mendirikan lembaga PAUD.

Peraturan Menteri Pendidikan dan Kebudayaan Nomor 84 tahun 2014 tentang Pendirian PAUD pasal 1 ayat 3 menyebutkan: "Satuan PAUD adalah Taman Kanak-kanak, Taman Kanak-kanak Luar Biasa, Kelompok Bermain, Taman Penitipan Anak, dan Satuan PAUD Sejenis.” Pasal tersebut menjelaskan bahwa lembaga PAUD itu tidak hanya pada TK melainkan juga bisa KB, TPA atau SPS. Berdasarkan data Satuan Pendidikan (NPSN) PAUD di seluruh Indonesia sampai 2019 (sekarang), lembaga TK/RA sejumlah 121.786, lembaga KB sejumlah 84.460, lembaga TPA 3.003, dan lembaga SPS 22.371 (https://referensi.data.kemdikbud.go.id/index21.php). Begitu banyak lembaga PAUD yang muncul di seluruh Indonesia mengindikasikan bahwa begitu banyak masyarakat yang peduli terhadap pendidikan sejak anak usia dini. Akan tetapi, pada kenyataannya tidak semua lembaga PAUD memiliki akreditasi dengan minimal baik (B). Sebagaimana data dari Badan Akreditasi Nasional PAUD PNF lembaga PAUD (TK/RA/SPS/TPA) yang tidak terakreditasi di seluruh Indonesia dari tahun 2017 ke tahun 2018 mengalami kenaikan dari 76 ke 327 lembaga. Selanjutnya, lembaga PAUD (TK/RA/SPS/TPA) yang terakreditasi "C" dari tahun 2017 ke 2018 mengalami peningkatan yang signifikan dari jumlah 3.974 lembaga menjadi 10.752 lembaga (http://banpaudpnf.kemendikbud.go.id) Data tersebut, menunjukkan bahwa adanya kemunduran dari segi kualitas lembaga PAUD. Sejatinya, akreditasi ini memiliki dampak positif terhadap kepercayaan masyarakat untuk menitipkan atau menyekolahkan ke lembaga tersebut (Sari, 2019, p. 131).

Data-data di atas menjadi suatu problem yang serius pada lembaga PAUD sehingga diperlukan suatu pemecahan masalah. Pemecahan masalah ini dapat dilakukan dengan cara menata ulang (re-desaign) manajemen pendirian lembaga PAUD. Manajemen pendirian PAUD adalah suatu proses mendirikan lembaga PAUD yang dilakukan dengan cara merencanakan, mengorganisasi, memimpin, dan mengendalikan sumber daya organisasi agar 
AWLADY: Jurnal Pendidikan Anak

Homepage: www.syekhnuriati.ac.id/jurnal/index.php/awlady

Email : pgrasyekhnurjati@gmail.com

P-ISSN: 2541-4658

E-ISSN: 2528-7427

tujuan yang diinginkan dapat tercapai sebagaiamana persyaratan yang telah ditentukan secara efektif dan efisien (Munastiwi, 2019, p. 31).

Manajemen pendirian PAUD yang baik sudah barang tentu akan menghasilkan kualitas lembaga yang baik juga. TK Islam Terpadu Mutiara Plus Banguntapan merupakan salah satu contoh lembaga PAUD dengan manajemen pendirian PAUD yang baik, dimana sejak awal pengajuan akreditasi sampai sekarang menempati peringkat "A". Pernyataan ini didapatkan dari hasil wawancara dengan kepala sekolah serta konsultan TK Islam Terpadu Mutiara Plus. Sehingga penting peneliti upayakan untuk mengkaji tentang manajemen pendirian lembaga PAUD supaya tetap konsisten berkualitas dengan menggunakan total quality management (TQM) approach.

\section{METODOLOGI}

Penelitian ini menggunakan penelitian kualitatif dengan pendekatan studi kasus. Pendekatan ini mencakup pada kehidupan nyata, dalam konteks atau setting kontemporer (Creswell, 2014, p. 135). Sumber data yang digunakan ada sumber primer dan sumber sekunder. Sumber primer yaitu kepala sekolah, guru, staff dan peserta didik. Sumber sekunder dalam bentuk arsip atau dokumen yang berkenaan dengan penelitian ini. Teknik mengumpulkan data yang dilakukan dengan observasi jenis partisipasi pasif, wawancara jenis semi-terstruktur, dan dokumentasi. Analisis data menggunakan model Milles and Huberman yang terbagi dalam reduksi data, penyajian data, dan penarikan kesimpulan. Dalam menguji keabsahan data penelitian ini menggunakan triangulasi sumber dan triangulasi teknik.

\section{HASIL DAN PEMBAHASAN}

Usia anak berada dalam masa golden age, waktu yang tepat untuk peletakan dasar dasar kepribadian anak. Apabila terjadi kelalaian dalam memberikan pelayanan pendidikan kepada anak maka anak akan kehilangan kesempatan emasnya, padahal masa tersebut tidak akan pernah terulang kembali. Dasar inilah yang menjadikan berdirinya TK IT Mutiara Plus sebagai upaya untuk mengabadikan ilmu. Filosofi mutiara menjadi simbol di TK ini memiliki makna sesuatu yang indah dan bernilai tinggi. Hal ini sesuai dengan mengapa anak dilahirkan, yakni amanah Allah swt. kebanggaan orang tua dan kekayaan yang tiada nilainya. Selanjutnya pada tahun ajaran 2013/ 2014 lembaga tersebut menjadi satu kesatuan lembaga PAUD Terpadu Mutiara Yogyakarta. 
AWLADY: Jurnal Pendidikan Anak

Homepage: www.syekhnuriati.ac.id/jurnal/index.php/awlady

Email : pgrasyekhnurjati@gmail.com

P-ISSN: 2541-4658

E-ISSN: 2528-7427

\section{Manajemen Pendirian Lembaga PAUD}

Kata manajemen berasal dari bahasa latin yaitu manusagree. Kata "manus" yang berarti "tangan" dan "agere” yang berarti "melakukan". Kata tersebut digabung menjadi kata kerja "managere" yang artinya "menangani". Menurut Parker Manajemen berarti seni melaksanakan pekerjaan melalui orang- orang (Usman, 2006, p. 3). Menurut pendapat lain kata manajemen berasal dari kata to manage berarti mengelola, memimpin atau mengarahkan.(Suyadi, 2011, p. 67) Menurut Rohiat sebagaimana dikutip oleh Ihsana E., pengertian dari manajemen adalah melaksanakan pengelolaan secara sistematis terhadap sumber daya dari sekolah atau organisasi.(El-Khuluqo, 2015, p. 7) Menurut Fari Ulfah, manajemen merupakan suatu upaya mengelola, mengatur, dan mengarahkan proses interaksi edukatif antara anak didik dan guru serta lingkungan secara tertatur, terencana dan tersistematis sebagai upaya untuk mewujudkan tujuan yang diinginkan (Ulfah, 2015, p. 26).

Hidayat (dalam Erni Munastiwi) manajemen adalah kegiatan untuk merencanakan, mengorganisasian, memimpin serta megendalikan sumber daya organisasi dan penggunaanya untuk mencapai tujuan yang didingkan secara efektif dan efisien.(Munastiwi, 2019, p. 31) Permendikbud No. 84 Tahun 2004 tentang Pendirian PAUD menjelaskan bahwa dalam mendirikan lembaga PAUD harus sesuai dengan prosedur dan persyaratan yang sesuai dengan peraturan Permendikbud yang telah ditentukan. Dengan demikian diartikan manajemen pendirian PAUD adalah suatu proses mendirikan lembaga PAUD yang dilakukan dengan cara merencanakan, mengorganisasi, memimpin, dan mengendalikan sumber daya organisasi agar tujuan yang diinginkan dapat tercapai sebagaiamana persyaratan yang telah ditentukan secara efektif dan efisien. Perlu diketahui bahwa masing-masing jalur pendidikan dan satuan pendidikan anak usia dini memiliki perbedaan prinsip penyelenggaraan. Secara detailnya dapat dilihat tabel di bawah ini:(Munastiwi, 2019, pp. 31-32)

Tabel. Prinsip Penyelenggaraan PAUD

\begin{tabular}{|c|c|c|c|}
\hline No. & $\begin{array}{l}\text { Jalur } \\
\text { Pendidikan }\end{array}$ & Satuan PAUD & Prinsip Penyelenggaraan \\
\hline \multirow[t]{3}{*}{1.} & Non Formal & $\begin{array}{l}\text { Satuan PAUD } \\
\text { Sejenis (SPS) }\end{array}$ & $\begin{array}{l}\text { Berbasis masyarakat (mudah, terjangkau } \\
\text { dan bermutu), dan keterlibatan orang tua/ } \\
\text { wali }\end{array}$ \\
\hline & & $\begin{array}{l}\text { Taman Penitipan } \\
\text { Anak (TPA) }\end{array}$ & Tempa, Asah, Asih, dan Asuh \\
\hline & & Kelompok Bermain & Ketersediaan \\
\hline
\end{tabular}


AWLADY: Jurnal Pendidikan Anak

Homepage: www.syekhnuriati.ac.id/jurnal/index.php/awlady

Email : pgrasyekhnurjati@gmail.com

P-ISSN: 2541-4658

E-ISSN: 2528-7427

\begin{tabular}{llrl}
\hline & & & \\
\cline { 3 - 5 } & & & \multicolumn{2}{c}{$\begin{array}{l}\text { kerjasama, kekeluargaan, keberlanjutan, } \\
\text { dan pembinaan berjenjang }\end{array}$} \\
\hline 2. Formal & Taman & Kanak- & Ketersediaan layanan transisional, \\
& kanak & $(\mathrm{TK}) /$ & kerjasama, kekeluargaan, keberlanjutan, \\
& Bustanul & Athfal & dan pembinaan berjenjang \\
& & (BA)/ Raudhatul & \\
& Athfal (RA) & \\
\hline
\end{tabular}

\section{Total Quality Manajemen (TQM)}

Definisi TQM merupakan pendekatan yang bersifat praktis yang strategis, karena fokus pada kebutuhan pelanggan dan kliennya dengan tujuan mencari hasil yang lebih baik (Sallis, 2006, p. 76). TQM memiliki ciri-ciri, yakni: memberi perhatian dan memuaskan customer, melaksanakan perbaikan berkelanjutan dalam jangka panjang, dan mengambil langkah dengan melibatkan seluruh eleman organisasi dan masyarakat (Hardjosoedarmo, 1997, p. 3). Adapun prinsip-prinsip TQM terdiri atas: kepuasan pelanggan, respek terhadap setiap orang, manajemen yang berdasar pada fakta, dan perbaikan yang berkesinambungan (Diana, 2003, pp. 14-15). Pertama, kepuasan pelanggan dalam pendidikan bisa disinonimkan dengan masyarakat sebagai dasar yang harus dilakukan dalam menjalankan suatu lembaga pendidikan. Semakin puas pelangkan lama kelamaan kepercayaan masyarakat pada lembaga pendidikan tersebut juga tinggi. Kedua, respek terhadap setiap orang artinya suatu lembaga pendidikan tidak semestinya melayani hanya orang-orang pilihan, namun melayani semua orang tanpa adanya deskriminasi. Ketiga, manajemen berdasar fakta artinya dalam memanajemen suatu lembaga pendidikan perlu transparan kepada seluruh elemen mulai dari internal sampai eksternal dari lembaga pendidikan itu sendiri. Keempat, perbaikan berkesinambungan artinya lembaga pendidikan ketika melakukan perbaikan tentu harus memiliki kesinambungan agar kualitasnya menjadi lebih maju bukan malah mundur.

Unsur-unsur pokok komponen TQM terdiri sepuluh unsur, yakni: fokus pada pelanggan, obsesi terhadap kualitas, pendekatan ilmiah, komitmen jangka panjang, kerjasama team, perbaikan sistem secara berkesinambungan, pendidikan dan pelatihan, kebebasan terkendali, kesatuan tujuan, dan adanya keterlibatan dan pemberdayaan karyawan (Diana, 2003, pp. 15-18). Faktor-faktor yang dapat menyebabkan kegagalan adalah delegasi dan kepemimpinan yang tidak baik, tim mania, proses penyebarluasan, menggunakan pendekatan 
AWLADY: Jurnal Pendidikan Anak

Homepage: www.syekhnuriati.ac.id/jurnal/index.php/awlady

Email : pgrasyekhnurjati@gmail.com

P-ISSN: 2541-4658

E-ISSN: 2528-7427

yang terbatas dan dogmatis, harapan yang terlalu berlebihan dan tidak realistis, serta empowerement yang bersifat prematur (Diana, 2003, pp. 19-20).

\section{Analisis Total Quality Management (TQM) dalam PAUD Terpadu Mutiara}

Prinsip-prinsip dalam TQM pada mulanya sering diterapkan dalam dunia industry, lembaga TK IT Mutiara Plus mencoba menerapkan prinsip-prinsip tersebut. Kepuasan pelanggan, respek terhadap setiap orang, manajemen yang berdasar pada fakta, dan perbaikan yang berkesinambungan diterapkan pada pendirian lembaga ini. Analisis TQM pada penelitian ini menggunakan prinsip yang dikemukakan oleh Diana, meliputi: kepuasaan pelanggan, respek terhadap setiap orang, manajemen yang berdasarkan fakta, dan perbaikan yang berkesinambungan (Diana, 2003, pp. 14-15).

\section{Upaya Menerapkan Prinsip Pemberian Kepuasan Pelanggan}

Upaya memberikan kepuasaan pelanggan salah satunya dengan memberikan layanan yang berbeda dari lembaga lain. Lembaga ini memiliki "Tujuh Pilar Pendidikan TK IT Mutiara Plus Yogyakarta. Ketujuh pilar tersebut adalah :

Pertama: Pendekatan Keislaman Secara Integratif. Kurikulum yang digunakan adalah kurikulum nasional, tidak berbeda dengan lembaga lain. Yang membedakan adalah pendekatannya. Semua materi dan kegiatan yang dilakukan berpusat pada nilai-nilai Islam secara integratif, sehingga tidak ada dikotomi, pemisahan antara ilmu agama dan ilmu umum. Dengan demikian terjadi proses internalisasi nilai keislaman dalam setiap kegiatan anak. Upaya ini menjadi kekhasan lembaga sehingga pelanggan dalam hal ini orangtua murid dapat melihat nilai plus lembaga dibandingkan dengan yang lain.

Kedua; Berpusat Pada Anak. Semua program kegiatan dirancang mengacu pada kebutuhan dan kondisi anak. Walaupun pelaksanaan kegiatan dilakukan secara klasikal, namun perhatian yang diberikan bersifat individu. Pembelajaran yang mengedepankan berpusat pada anak ini sesuai dengan prinsip TQM berkaitan dengan respek terhadap setiap orang.

Ketiga; Meliputi Seluruh Aspek Kepribadian. Aspek yang dikembangkan bukan hanya kognitif saja. Melainkan seluruh aspek kepribadian anak. Bukan hanya kecerdasan intelektual saja (IQ), tapi juga pusat kecerdasan yang lain seperti kecerdasan emosional dan kecerdasan spiritual. 
AWLADY: Jurnal Pendidikan Anak

Homepage: www.syekhnuriati.ac.id/jurnal/index.php/awlady

Email : pgrasyekhnurjati@gmail.com

P-ISSN: 2541-4658

E-ISSN: 2528-7427
Vol. 6, No. 2, September 2020

Keempat; Belajar Sambil Mencoba (Learning by doing). Semua fasilitas dan setiap peristiwa disikapi sebagai sumber ilmu, dalam upaya memahami kebesaranNya, Hal ini didekati dengan praktik nyata, anak mencoba dan merasakan secara langsung, sehingga terhindar dari pemahaman semu dan sebatas kognitif semata.

Kelima; Pembiasaan (Habbit Forming). Pembentukan kepribadian yang positif dan tangguh memerlukan proses panjang. Tahap awal diperlukan latihan secara berulang dan terns menerus. Pengabaian terhadap aspek ini menimbulkan kepribadian yang pecah, yakni menyadari akan nilai kebajikan, namun tidak mampu mengamalkan karena tidak terbiasa. Habbit Forming ini menjadi keunggulan lembaga sebagai wujud pelayanan untuk memberikan kepuasan kepada pelanggan dalam hal ini orangtua siswa. Keberadaan program ini memberikan pernyataan bahwa siswa yang masuk pada lembaga ini akan diberikan bimbingan kepribadian yang positif.

Keenam; Keteladanan (Uswatun Hasanah). Anak adalah peniru ulung. Dia akan menirukan segala yang dilihat dari Orang yang dikagumi. Orang tua adalah guru pertama dan utama, sedang pendidik adalah guru kedua. Dalam Program keteladan, Guru di lembaga ini bukan sekedar sumber ilmu, melainkan sumber belajar secara menyeluruh. Untuk itu diperlukan guru yang mampu menjadi figur dan contoh tauladan bagi anak.

Ketujuh; Program Full Day. Sebagai konsekuensi dari konsep diatas, maka dibutuhkan rentang waktu yang lebih panjang (plus). Seperti konsep "praktik langsung" dan “pembiasaan”. Sebagai contoh, aktivitas 'sholat' dan 'makan', tidak cukup hanya teori saja, namun perlu dipraktikkan secara langsung dan dibiasakan setiap hari, sehingga berbentuk kebiasaan dan nilai positif yang menyatu dalam diri anak. Program Full day menjadi bentuk pelayanan optimal untuk memuaskan pelanggan mengingat semakin banyak permintaan lapangan untuk full day school.

Upaya lain dalam bentuk memberikan pelayanan optimal sebagai prinsip TQ yang dilakukan lembaga adalah adanya program penjajagan kemampuan anak yang dimaksudkan untuk mengetahui tahap kemandirian dan perkembangan siswa. Kegiatan ini dapat dijadikan acuan lembaga serta orangtua dalam langkah selanjutnya terkait perkembangan anak. Program lain yakni wawancara orangtua, program ini umum dilakukan, namun lembaga ini 
AWLADY: Jurnal Pendidikan Anak

Homepage: www.syekhnuriati.ac.id/jurnal/index.php/awlady

Email : pgrasyekhnurjati@gmail.com

P-ISSN: 2541-4658

E-ISSN: 2528-7427

menerapkan wawancara untuk fokus membangun komitmen bersama antara orangtua dan lembaga.

\section{Pembelajaran Sentra sebagai bentuk Pelayanan Optimal}

Pada pelaksanaan pembelajaran, Lembaga menerapkan sistem kelas sentra. Dimulai dari Tahun Pelajaran 2010/2011 TK IT Mutiara Plus Yogyakarta menggunakan pembelajaran dengan Pendekatan BCCT (Beyond Centre and Circle Time) guna mengoptimalkan potensi individual anak didiknya. Dalam sistem pembelajaran dengan pendekatan BCCT ini materi pembelajaran disampaikan secara tersentral sekaligus terintegrasi. Tersentral maksudnya anak belajar dengan system kelas-kelas (sentra) sehingga anak diharapkan dapat menggali potensi individual berupa pengalaman dengan mengalami secara langsung dalam sebuah kelas yang sudah disetting pendidik sesuai dengan pengalaman yang ingin diberikan kepada anak didiknya. Dan setiap hari anak masuk di kelas yang berbeda dengan guru pembimbing serta permainan-permainan yang berbeda, sehingga anak tidak akan merasa bosan. Sedangkan terintegrasi maksudnya indikator-indikator kemampuan yang diharapkan tercapai oleh anak disajikan secara menyenangkan tanpa tekanan dan paksaan sesuai dengan minat anak, guru berperan sebagai motivator saja, apabila anak tidak berminat pada hari ini, kemampuan tersebut akan diperolehnya pada hari dan sentra berikutnya. Dalam kegiatan sentra ini tiaptiap kelompok akan didampingi oleh 1 orang guru kelas yang akan selalu mendampingi. Sedangkan guru sentra tugasnya sebagai koordinator sentra yang secara khusus mengelola pembelajaran di sentra tersebut saja. Dan anak didik secara terjadwal belajar di kelas yang berbeda secara bergilir, sehingga dalam 1 minggu anak masuk di sentra tertentu satu kali saja.

Berikut beberapa sentra yang dimiliki lembaga PAUD Terpadu Mutiara sebagai bentuk pelayanan untuk optimalisasi perkembangan anak: Sentra Persiapan, sentra peran micro, sentra peran makro, sentra balok, sentra IMTAQ, sentra seni dan kreativitas.

Kegiatan sentra memiliki implikasi terhadap kecakapan hidup yang dimiliki anak. Sentra lain yang dimiliki lembaga ini antara lain:

Sentra sains, Tempat bermain sambil belajar yang ditujukan untuk memberikan pengalaman melalui pengamatan dan percobaan. Di sentra ini anak belajar melalui kegiatan yang mencakup kegiatan menelusuri, mengamati dan melaksanakan percobaan. Kegiatan sains dapat mengembangkan kemampuan eksplorasi dan investigasi. yaitu kegiatan untuk 
AWLADY: Jurnal Pendidikan Anak

Homepage: www.syekhnuriati.ac.id/jurnal/index.php/awlady

Email : pgrasyekhnurjati@gmail.com

P-ISSN: 2541-4658

E-ISSN: 2528-7427
Vol. 6, No. 2, September 2020

310

mengamati dan menyelidiki objek serta fenomena alam, mengukur serta mengkomunikasikan hasil pengamatan. Dampaknya adalah anak mampu memahami pengetahuan tentang berbagai benda baik ciri, struktur maupun fungsinya. Mengembangkan rasa ingin tahu, rasa senang dan mau melaksanakan kegiatan penemuan.

Sentra cooking, Tempat bermain sambil belajar untuk mengenal kegiatan sehari-hari, melalui proses pengolahan makanan yang berawal dari pengcnalan bahan makanan, cara mcmbersihkan, cara pengolahan, serta penyajian makanan. Kegiatan di sentra ini dilaksanakan dalam bentuk praktek, dimana anak diajak secara langsung untuk memasak. Dengan harapan anak mau makan makanan yang bervariasi, mengenal nama dan fungsi alat-alat disekitat anak. Dampaknya adalah anak terbiasa makan makanan dengan bermacam-macam jenis, anak mampu memilih makanan yang sehat dan bergizi serta mengenal fungsi dan manfaat makan bagi tubuh.

Sentra bahan alam, Tempat bermain sambil belajar yang mana menggunakan bahanbahan dan alat-alat main yang memungkinkan organ-organ sensorimotor anak bekerja untuk mengenal, mengeksplorasi, dan menemukan pengetahuan atau konsep yang berkaitan dengan bendabenda yang ada disekitamya dengan bahan alam atau barang bekas. Di sentra Bahan Alam, anak berkesempatan mengenal sifat-sifat benda, mengamati, menyentuh, memegang, merasakan tekstumyajuga menemukan pengalaman-pengalaman tentang kejadian dan hubungan sebab akibat melalui interaksi dengan bahanbahan dan alat-alat yang digunakan. Efek yang diharapkan: Mendorong rasa ingin tahu anak pada bendabenda. Anak dapat terstimulasi aspek motorik halusnya secara optimal dan kemampuan menganalisa sejak dini serta mengenal keaksaraan.

Sentra multimedia. Anak anak dapat bermain sambil belajar untuk pengenalan IT sederhana yang digunakan dalam media pembelajaran yang memungkinkan untuk mengembangkan wawasan dan keterampilan menggunakan teknologi sederhana. Di sentra ini, anak mengenal beberapa ilmu pengetahuan melalui beberapa media yang menarik baik dalam bentuk bacaan, gambar juga film edukasi. Efek yang diharapkan: Anak memiliki kemampuan penguasaan IT yang baik/ tidak gaptek. Anak memiliki kemampuan memanfaatkan IT sesuai dengan fungsinya. Keberadaan kelas sentra yang cukup variatif ini menjadi satu kelebihan tersendiri dari TK Mutiara. 
AWLADY: Jurnal Pendidikan Anak

Homepage: www.syekhnuriati.ac.id/jurnal/index.php/awlady

Email : pgrasyekhnurjati@gmail.com

P-ISSN: 2541-4658

E-ISSN: $2528-7427$
Vol. 6, No. 2, September 2020

\section{Akreditasi Unggul sebagai Bentuk Prinsip Perbaikan Lembaga Berkesinambungan}

Setelah TPA, KB dan TK Mutiara memperoleh ijin dari departemen Pendidikan Nasional, maka segera dilakukan pembenahan dan peningkatan kwalitas lebih lanjut Salah satu kriteria lembaga yang berkwalitas adalah mendapatkan penilaian dari pemerintah dalam bentuk akreditasi. Maka setelah 2 tahun berdiri, lembaga Mutiara mengajukan diri untuk dapat diakreditasi. Dari penilaian yang dilakukan pada tanggal 15 Desember 2007 TK IT Mutiara yogyakarta telah terakreditasi dengan nilai 97,38 'sangat bagus bagus). Pemerolahan akreditasi yang unggul menandakan adanya upaya lembaga ini dalam melakukan perbaikan manajemen lembaga secara berkesinambungan. TK IT Mutiara Plus tidak memiliki badan pengawas khusus untuk memberikan masukan terhadap manajemen lembaga. Dinas Pendidikan Kabupaten Bantul yang melakukan pengawasan terhadap lembaga sehingga lembaga dapat melakukan perbaikan berkesinambungan berdasarkan masukan dari dinas terkait.

\section{Respek terhadap Setiap Orang}

Berdasarkan hasil observasi lembaga TKIT Mutiara Plus sangat respect kepada siapapun. Hal ini terbukti lembaga sekolah tersebut menerima perserta didik yang memiliki kebutuhan khusus (special). Terlebih lagi peserta didik yang kurang mampu mendapatkan beasiswa pemotongan biaya Pendidikan. Selanjutnya, masyarakat sekitar lembaga TK IT Mutiara juga mendapatkan beasiswa pemotongan biaya pendidikan.

\section{Manajemen Berdasarkan Fakta}

Lembaga TK IT Mutiara Plus sangat transparan kepada para orang tua dan wali murid. Hal ini dimaksudkan supaya orang tua atau wali murid mengetahui dan memahami kondisi lembaga tersebut, sehingga kerjasamanya dapat terjalin dengan baik.

\section{SIMPULAN}

Berdasarkan paparan di atas dapat disimpulkan bahwa TKIT Mutiara Plus Banguntapan, Bantul menerapkan Total Quality Management (TQM) dengan baik dengan dibuktikan begitu lengkap gambaran lembaga tersebut. Dimana, lembaga tersebut bermula dari siswa yang sedikit sekarang menjadi banyak. Selain itu, perbaikan yang dilakukan pun berkesinambungan dan pelayanan yang dilakukan juga memuaskan serta tetap konsisten 
AWLADY: Jurnal Pendidikan Anak

Homepage: www.syekhnurjati.ac.id/jurnal/index.php/awlady

Email : pgrasyekhnurjati@gmail.com

P-ISSN: 2541-4658

E-ISSN: 2528-7427
Vol. 6, No. 2, September 2020

selalu memperbaiki kualitas lembaga tersebut. Berawal dari pembelajaran klasikal menjadi pembelajaran bermodel sentra dengan penjabaran sentra yang lebih dari cukup.

\section{DAFTAR PUSTAKA}

Crawford, L. E. d., \& Shutler, P. (1999). Total quality management in education: Problems and issues for the classroom teacher. International Journal of Educational Management, 13(2), 67-73. https://doi.org/10.1108/09513549910261122

Creswell, J. W. (2014). Qualitative Analysis diterjemahkan oleh Ahmad Lintang dan Lizuardi. Yogyakarta: Pustaka Pelajar.

Diana, F. T. \& A. (2003). Total Quality Manajemen (Revisi). Yogyakarta: Andi.

El-Khuluqo, I. (2015). Manajemen PAUD “Pendidikan Taman Kanak-kanak." Yogyakarta: Pustaka Pelajar.

Gaspersz, V. (2002). Total Quality Management. Yogyakarta: Gramedia Pustaka Utama.

Hardjosoedarmo, S. (1997). Dasar-dasar Total Quality Management. Yogyakarta: Andi.

Mesiono. (2017). Manajemen Pendidikan Radhatul Athfal (RA). Depok: Prenada Media Group.

Mulyasa, E. (2014). Manajemen PAUD. Bandung: PT Remaja Rosdakarya.

Munastiwi, E. (2019). Manajemen Lembaga PAUD. Yogyakarta: Pendidikan Islam Anak Usia Dini Fakultas Ilmu Tarbiyah dan Keguruan UIN Sunan Kalijaga Yogyakarta.

Salih, T. (2008). Total Quality Management in Education. Zanco Journal, the Scientific Journal of Salahaddin University-Arbil, (36).

Sallis, E. (2006). Total Quality Management in Education. Yogyakarta: IRCiSoD.

Sari, R. P. (2019). Dampak Akreditasi terhadap Mutu PAUD di KB Al-Amin di Desa Sumber Bendo Kecamatan Bantur Kabupaten Malang. Jurnal Tinta, 1(1), 117-133.

Suyadi. (2011). Manajemen PAUD TPA-KB-TK/RA. Yogyakarta: Pustaka Pelajar.

Töremen, F., Karakuş, M., \& Yasan, T. (2009). Total quality management practices in Turkish primary schools. Quality Assurance in Education, 17(1), 30-44. https://doi.org/10.1108/09684880910929917

Ulfah, F. (2015). Manajemen PAUD. Yogyakarta: Pustaka Pelajar.

Usman, H. (2006). Manajemen (Teori, Praktek, dan Riset Pendidikan). Jakarta: Sinar grafika offset. 